\title{
Multi-stimuli Control over Assembly and Guest Binding in Metallo- supramolecular Hosts Based on Dithienylethene Photoswitches
}

\author{
Ru-Jin Li, Jacopo Tessarolo, ${ }^{\ddagger}$ Haeri Lee, and Guido H. Clever*
}

Cite This: J. Am. Chem. Soc. 2021, 143, 3865-3873

Read Online

ABSTRACT: It is difficult to assemble multi-component metallosupramolecular architectures in a non-statistical fashion, which limits their development toward functional materials. Herein, we report a system of interconverting bowls and cages that are able to respond to various selective stimuli (light, ligands, anions), based on the self-assembly of a photochromic dithienylethene (DTE) ligand, $\mathbf{L}^{\mathbf{a}}$, with $\mathrm{Pd}^{\mathrm{II}}$ cations. By combining the concept of "coordination sphere engineering", relying on bulky quinoline donors, with reversible photoswitching between the ligand's open $\left(o-\mathrm{L}^{\mathbf{a}}\right)$ and closed $\left(c-\mathbf{L}^{\mathbf{a}}\right)$ forms, a $\left[\mathrm{Pd}_{2}\left(o-\mathbf{L}^{\mathbf{a}}\right)_{4}\right]$ cage $(o-\mathbf{C})$ and a $\left[\mathrm{Pd}_{2}\left(c-\mathbf{L}^{\mathrm{a}}\right)_{3}\right]$ bowl $(c-\mathbf{B})$ were obtained, respectively. This structural rearrangement modulates the system's guest uptake capabilities.

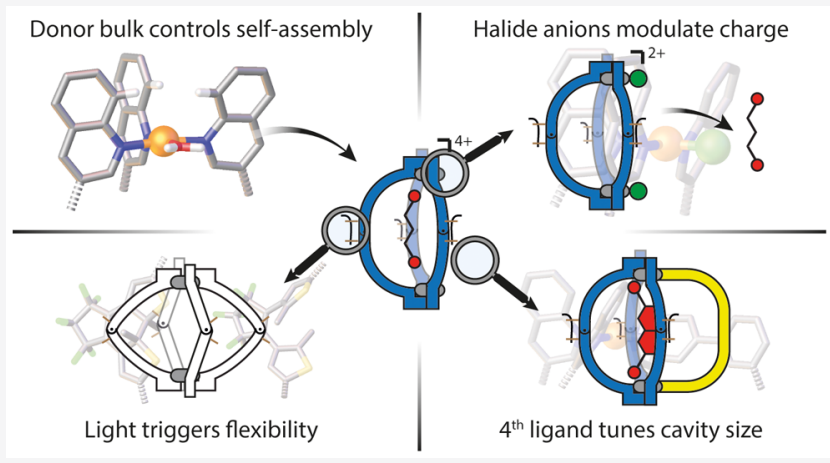
Among three bis-sulfonate guests (G1, G2, and G3), the cage can encapsulate only the smallest (G1), while the bowl binds all of them. Bowl $c$-B was further used to synthesize a series of heteroleptic cages, $\left[\mathrm{Pd}_{2} \mathrm{~L}_{3}{ }_{3} \mathrm{~L}^{\mathrm{B}}\right]$, representing a motif never reported before. Additional ligands $\left(\mathrm{L}^{\mathrm{c}-\mathrm{f}}\right)$, with short or long arms, tune the cavity size, thus enabling or preventing guest uptake. Addition of $\mathrm{Br}^{-} / \mathrm{Ag}^{+}$makes it possible to change the overall charge, again triggering guest uptake and release, as well as fourth ligand de-/recomplexation. In combination, site-selective introduction of functionality and application of external stimuli lead to an intricate system of hosts with different guest preferences. A high degree of complexity is achieved through cooperativity between only a few components.

\section{INTRODUCTION}

Natural systems are capable of fabricating supramolecular assemblies with multiple components in a precise and controlled manner. For example, ribosomes and virus capsids are assembled in a non-covalent fashion, starting from smaller building blocks. To mimic the function and complexity of natural nanostructures, chemists have developed supramolecular self-assembly, a field that has become a burgeoning area of study. ${ }^{1}$ In particular, the design of coordination-driven architectures represents a powerful strategy. Owing to the directionality and reversibility of the metal-ligand bond, it is possible to create a plethora of architectures with different sizes, shapes, and functions. ${ }^{2}$ In the past years, metallacages have received great attention due to their peculiar structures ${ }^{3}$ and promising functions, ${ }^{4}$ e.g., in selective recognition ${ }^{5}$ and catalysis. ${ }^{6}$ However, while most natural assemblies are complex multi-functional systems comprising several different building blocks, most artificial metallo-supramolecular assemblies known today are highly symmetric structures, formed from only one type of ligand. Increasing such a system's complexity via the introduction of multiple different ligands is challenging, since metal-mediated self-assembly under thermodynamic control easily results in a statistical mixture of products. ${ }^{7}$ In recent years, several strategies to combine distinguishable ligands in a non-statistical fashion, leading to the clean assembly of heteroleptic cages, have been reported. For example, the Yoshizawa group explored the use of a templating guest, ${ }^{8}$ Crowley et al. took advantage of hydrogen-bonding between adjacent ligands, ${ }^{9}$ and Zhou, ${ }^{10 a}$ Fujita, ${ }^{10 b}$ Mukherjee, ${ }^{10 c, d}$ Chand, ${ }^{10 e, f}$ and our group ${ }^{10 g-i}$ utilized geometric principles to form heteroleptic cages containing two different types of ligands. Recently, our group set out to investigate a "coordination sphere engineering" approach based on the introduction of steric hindrance around the metal centers to increase the structural complexity in a series of $\mathrm{Pd}^{\mathrm{II}}$-mediated assemblies. On one hand, banana-shaped ditopic ligands with picoline donors allowed us to form cis-configured $\left[\mathrm{Pd}_{2} \mathrm{~L}_{2}^{\mathrm{A}} \mathrm{L}_{2}^{\mathrm{B}}\right]^{4+}$ cages, ${ }^{11}$ while the introduction of quinoline or acridine donor groups resulted in the assembly of $\left[\mathrm{Pd}_{2} \mathrm{~L}_{3} \mathrm{X}_{2}\right]$ bowl-shaped structures or $\left[\mathrm{Pd}_{2} \mathrm{~L}_{2} \mathrm{X}_{4}\right]$ rings, respectively $(\mathrm{X}=$ solvent or halide anion). ${ }^{12}$ Despite these few examples, rational multi-component assembly to give a single product remains

Received: December 2, 2020

Published: March 5, 2021 


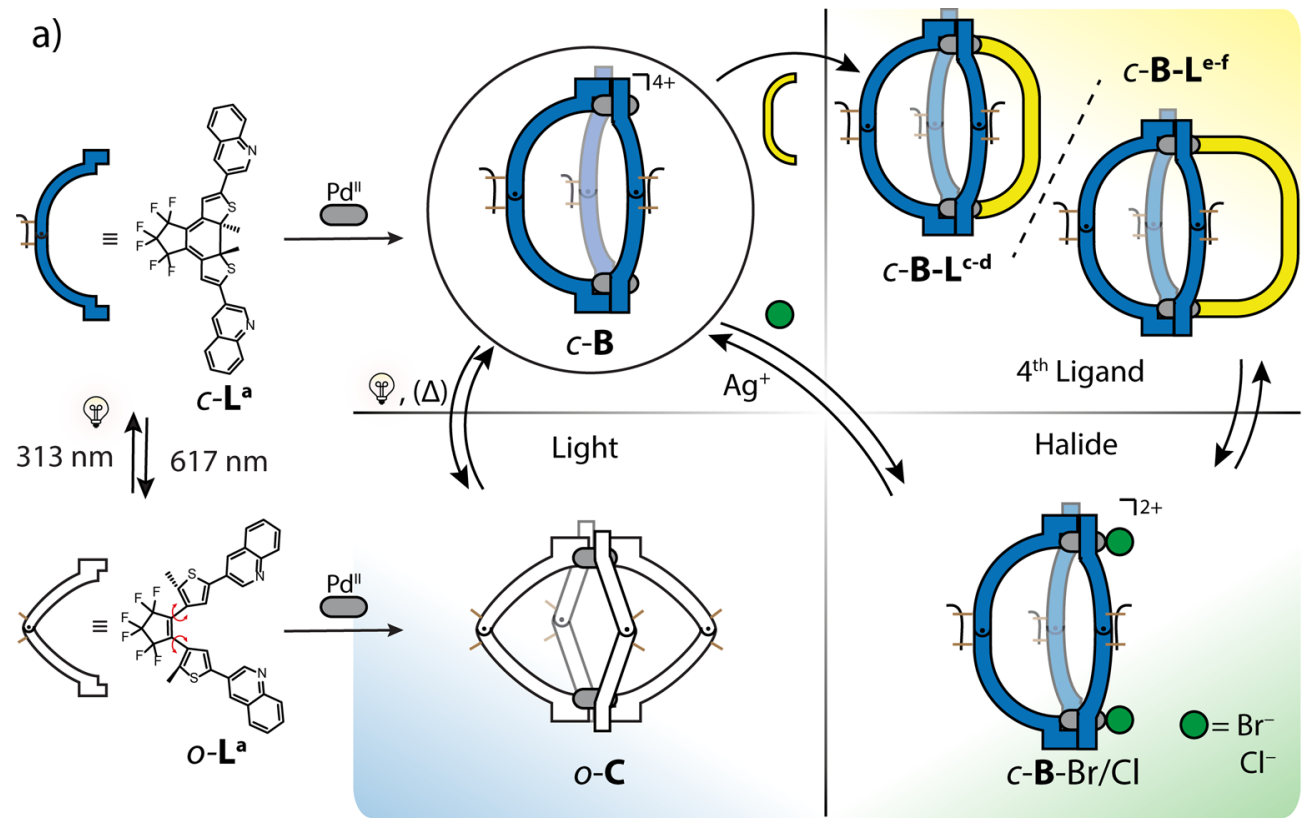

b)
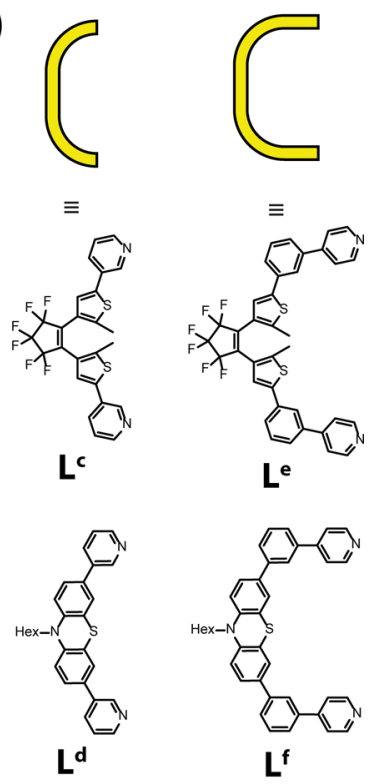

Figure 1. (a) Self-assembly of $\mathbf{L}^{\mathbf{a}}$ with $\mathrm{Pd}^{\mathrm{II}}$ to form a $\left[\mathrm{Pd}_{2} \mathbf{L}_{4}^{\mathrm{a}}\right]$ cage $(o-\mathbf{C})$ or a $\left[\mathrm{Pd}_{2} \mathbf{L}_{3}{ }_{3}\right]$ bowl $(c-\mathbf{B})$ that reacts to multiple stimuli: light triggers reversible structural rearrangement between $c-\mathbf{B}$ and $o-\mathbf{C}$ (blue panel), halides substitute solvents to saturate the $\mathrm{Pd}^{\mathrm{II}}$ coordination environments while reducing the overall charge from $4+$ to $2+$ (green panel), and addition of pyridine-based fourth ligands leads to $\left[\mathrm{Pd}_{2} \mathrm{~L}_{3}^{\mathrm{A}} \mathrm{L}^{\mathrm{B}}\right]$ heteroleptic cages $\left(c-B-L^{c-f}\right)$ (yellow panel). (b) List of short- $\left(\mathbf{L}^{\mathrm{c}, \mathrm{d}}\right)$ and long-arm $\left(\mathrm{L}^{\mathrm{e}, \mathrm{f}}\right)$ bis-pyridyl ligands.

challenging. ${ }^{13}$ Even more so, exploiting the multi-ligand character of heteroleptic cages to introduce functional complexity is still largely unexplored, in particular with respect to emergent properties resulting from an interplay of different components. Owing to their dynamic behavior and the presence of an accessible cavity, coordination cages with stimuli-responsive functionality represent a promising platform to develop novel materials ${ }^{14}$ and adaptive host-guest systems. $^{15}$

It has been shown that interaction of such cages with chemical stimuli, e.g., additional ligands, allows structural rearrangement and guest release. ${ }^{16}$ The addition of halide anions to positively charged hosts can trigger the uptake of neutral guest molecules. ${ }^{17}$ Guest uptake can also be tuned in redox-responsive systems. ${ }^{18}$ Sophisticated $\mathrm{pH}$ effects have recently been investigated ${ }^{19}$ and combined with light, leading to reversible cage disassembly. ${ }^{20}$ Light as a waste-free, precisely administered external stimulus has gained high popularity in the control of supramolecular systems. ${ }^{14 a, 21}$ We previously reported light-responsive cages in which photochromic dithienylethene (DTE) ligands made it possible to control structural rearrangements as well as guest uptake and release in a fully reversible fashion. ${ }^{22}$ Most reported examples of stimuliresponsive, metallo-supramolecular systems are based on homoleptic structures, though. ${ }^{23}$ Hence, the introduction of more than one functionality or response to more than one stimulus is a challenge.

We herein demonstrate that multi-stimuli-responsive systems can be realized by combining three well-established trigger elements via non-statistical, heteroleptic self-sorting. We combine a strategy we coined "coordination sphere engineering" in tandem with light-responsive DTE backbones to achieve the self-assembly of an interconvertible pair of $\left[\mathrm{Pd}_{2} \mathrm{~L}_{4}^{\mathrm{A}}\right]$ cage- and $\left[\mathrm{Pd}_{2} \mathrm{~L}_{3}^{\mathrm{A}}\right]$ bowl-shaped hosts, the former deriving from the open-form photoisomer $\left(o-\mathrm{L}^{\mathbf{a}}\right)$ and the latter from the closed isomer $\left(c-\mathbf{L}^{\mathbf{a}}\right.$; Figure $\left.1 \mathrm{a}\right)$. The latter system then serves as a platform for the non-statistical formation of a series of heteroleptic cages $\left[\mathrm{Pd}_{2} \mathrm{~L}_{3}^{\mathrm{A}} \mathrm{L}^{\mathrm{B}}\right]$ with tunable cavity size and guest binding affinity (Figure 1a, yellow panel). Besides its susceptibility to light, the system shows stimuli-responsive behavior triggered by chemical species (fourth ligands $\mathrm{L}^{\mathrm{B}}$ and halide anions), making it possible to differentiate a series of anionic guests and control their uptake and release.

\section{RESULTS AND DISCUSSION}

Self-Assembly of Homoleptic Cages and Bowls. The general design of the system is based on previous work from our group on photochromic $\left[\mathrm{Pd}_{2} \mathrm{~L}_{2 n}\right]$ assemblies formed from banana-shaped bis-pyridine ligands having DTE backbones. ${ }^{14 a, 21}$ In this work, we combine the effect of the photochromic backbones with coordination sphere engineering by installing quinolin-3-yl donor groups that introduce significant steric hindrance around the coordinated $\mathrm{Pd}^{\mathrm{II}}$ cations. We had shown previously that, in such quinoline-based assemblies, a fine balance separates the formation of sterically less crowded $\left[\mathrm{Pd}_{2} \mathrm{~L}_{3}\right]$ bowl-shaped structures and more constrained $\left[\mathrm{Pd}_{2} \mathrm{~L}_{4}\right]$ cages. ${ }^{12}$ Here, we show how this balance can be tipped by photoisomerizing the ligand backbones in one direction or the other. Ligand $o-\mathbf{L}^{\mathbf{a}}$ was synthesized by a Suzuki cross-coupling reaction of perfluoro-1,2-bis(2-iodo-5-methylthien-4-yl)cyclopentene and 2 equiv of quinolin-3-yl boronic acid. Selfassembly of $o-\mathrm{L}^{\mathbf{a}}$, with the photoswitch in its open form, and $\left[\mathrm{Pd}\left(\mathrm{CH}_{3} \mathrm{CN}\right)_{4}\right]\left(\mathrm{BF}_{4}\right)_{2}$ in a $2: 1$ ratio in $\mathrm{CD}_{3} \mathrm{CN}$ at $70{ }^{\circ} \mathrm{C}$ led to the quantitative formation of cage compound $\left[\mathrm{Pd}_{2}\left(o-\mathrm{L}^{\mathrm{a}}\right)_{4}\right]^{-}$ $\left(\mathrm{BF}_{4}\right)_{4} \quad(o-\mathrm{C}$; Figure $1 \mathrm{a}$, blue panel). Assembly was unambiguously confirmed by NMR spectroscopy and highresolution electrospray ionization mass spectrometry (HR-ESIMS) (Figure 2a,c) as well as single-crystal X-ray structure determination (Figure 3a). Slow vapor diffusion of $\mathrm{Et}_{2} \mathrm{O}$ into a $\mathrm{CD}_{3} \mathrm{CN}$ solution of $o-\mathrm{C}$ allowed us to grow single crystals suitable for synchrotron diffraction analysis. The compound crystallized in the tetragonal space group $\mathrm{P4}_{2}$, and the structure 


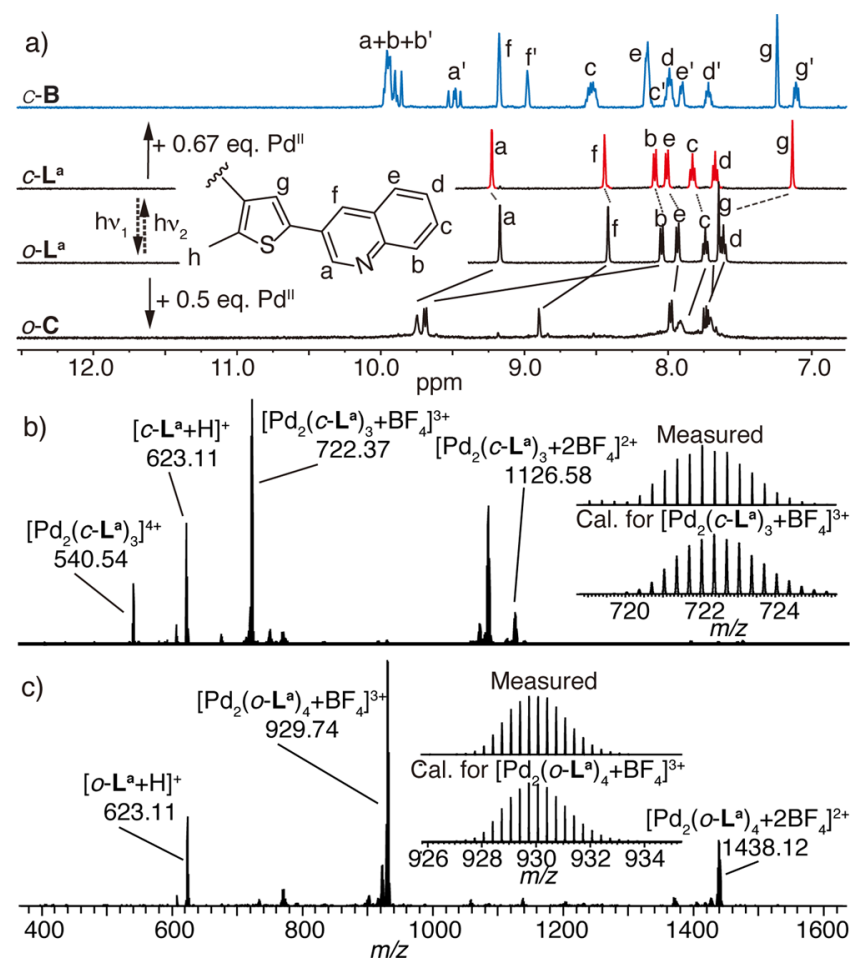

Figure 2. (a) ${ }^{1} \mathrm{H}$ NMR spectra $\left(500 \mathrm{MHz}, \mathrm{CD}_{3} \mathrm{CN}, 298 \mathrm{~K}\right)$ of ligands $o-\mathbf{L}^{\mathbf{a}}, c-\mathbf{L}^{\mathrm{a}}, o-\mathbf{C}$, and $c-\mathbf{B}$. (b, c) ESI-MS spectra of (b) $c-\mathbf{B}$ with isotope pattern of $\left[c-B+B_{4}\right]^{3+}$ shown in the inset and (c) $o-\mathbf{C}$ with isotope pattern of $\left[o-\mathrm{C}+\mathrm{BF}_{4}\right]^{3+}$.

was confirmed to be a $\left[\mathrm{Pd}_{2} \mathrm{~L}_{4}\right]$ cage. Compared with our reported $\left[\mathrm{Pd}_{2} \mathrm{~L}_{4}\right]$ DTE-based cage derivatives, ${ }^{21}$ in $o-\mathrm{C}$, the $C_{2}-$ symmetric ligands are all slightly helically twisted along the $\mathrm{Pd}-\mathrm{Pd}$ axis, presumably helping to release steric hindrance around the two coordination centers. This becomes clear by measuring the angles between the normals to the plane created by $\mathrm{Pd}$ and the four coordinating $\mathrm{N}$ atoms and the quinoline plane, having an averaged value of about $74^{\circ}$, as compared to $88^{\circ}$ for our previously reported pyridyl-DTE cage (further details in the Supporting Information, Figure S121). Cage o-C features a pair of $P P P P / M M M M$ enantiomers in the crystal structure (Figure S52). ${ }^{24}$ Irradiation of a $\mathrm{CD}_{3} \mathrm{CN}$ solution of $o$ $\mathbf{L}^{\mathbf{a}}$ using $313 \mathrm{~nm}$ light allows conversion into $c-\mathbf{L}^{\mathbf{a}}$ with $>99 \%$ yield. Reacting $c-\mathrm{L}^{\mathrm{a}}$, featuring the photoswitch in its closed form, with $\left[\mathrm{Pd}\left(\mathrm{CH}_{3} \mathrm{CN}\right)_{4}\right]\left(\mathrm{BF}_{4}\right)_{2}$ in a $3: 2$ ratio at $70{ }^{\circ} \mathrm{C}$ led to the formation of the bowl-shaped structure $\left[\mathrm{Pd}_{2}\left(c-\mathbf{L}^{\mathrm{a}}\right)_{3}\right.$ (Solvent) $\left.{ }_{2}\right]\left(\mathrm{BF}_{4}\right)_{4}(c-\mathbf{B})$ (Figure 1a). The first result corroborating the bowl structure came from NMR analysis, since the ${ }^{1} \mathrm{H}$ spectrum clearly shows two sets of signals in a 2:1 ratio (Figure 2a, Figure S13).

Due to symmetry reasons, one set of signals is expected to derive from the middle ligand, while the second set can be assigned to the two ligands flanking the side of the bowl structure. ${ }^{12 a}$ Moreover, ${ }^{1} \mathrm{H}$ DOSY NMR (298 K) further confirmed the presence of a single species in solution (Figure S17). As configurationally stable ligand $c-\mathbf{L}^{\mathbf{a}}$ was used in its racemic form, we would expect bowl $\boldsymbol{c}$-B to exist in six diastereomeric forms, producing altogether four sets of ${ }^{1} \mathrm{H}$ NMR signals, each representing a unique chemical environment (see details in Supporting Information, Figure S52). Indeed, a 4-fold signal splitting was observed for protons $\mathrm{H}_{\mathrm{a}^{\prime}}$ and $\mathrm{H}_{\mathrm{g}^{\prime}}$ (Figure 2a, Figure S55). When the structure was assembled from enantiopure $R, R-c-\mathbf{L}^{\mathbf{a}}$ or $S, S-c-\mathbf{L}^{\mathbf{a}}$ (resolved by
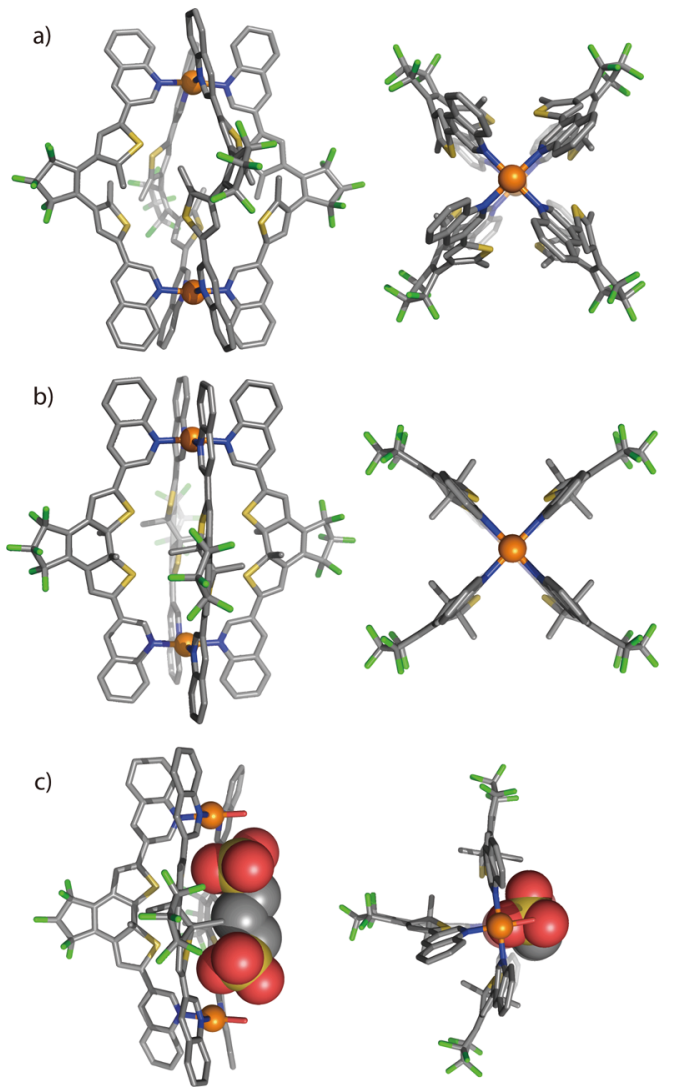

Figure 3. X-ray structures of (a) o-C, (b) c-C, and (c) host-guest complex G1@c-B (fourth $\mathrm{Pd}^{\mathrm{II}}$ positions coordinated by $\mathrm{H}_{2} \mathrm{O}$ ) in side (left) and top (right) views. All hydrogen atoms, solvent molecules, counteranions, and minor disorders are omitted for clarity. In $c$ - $\mathbf{C}$ and G1@c-B, all backbone methyl groups are disordered over both possible positions with approximately $50 \%$ occupancy (here only one diastereomer is shown; C gray, $\mathrm{N}$ blue, $\mathrm{F}$ green, $\mathrm{S}$ yellow, $\mathrm{O}$ red, $\mathrm{Pd}$ orange).

chiral HPLC), however, much clearer and sharper 1D and 2D ${ }^{1} \mathrm{H}$ NMR spectra were obtained (Figures S55-S57). Further confirmation of the bowl structure arose from HR-ESI-MS, in which a series of prominent peaks assigned to the bowl with a variable number of $\mathrm{BF}_{4}{ }^{-}$counterions were clearly detected $\left(\left[\mathrm{Pd}_{2}\left(c-\mathbf{L}^{\mathrm{a}}\right)_{3}\right]^{4+},\left[\mathrm{Pd}_{2}\left(c-\mathrm{L}^{\mathrm{a}}\right)_{3}+\mathrm{BF}_{4}\right]^{3+}\right.$, and $\left.\left[\mathrm{Pd}_{2}\left(c-\mathrm{L}^{\mathrm{a}}\right)_{3}+2 \mathrm{BF}_{4}\right]^{2+}\right)$ (Figure 2b). Interestingly, when $c-\mathbf{L}^{\mathrm{a}}$ and $\mathrm{Pd}^{\mathrm{II}}$ cations are reacted in the correct stoichiometry to form a $\left[\mathrm{Pd}_{2} \mathrm{~L}_{4}\right]^{2+}$ cage, ${ }^{1} \mathrm{H}$ NMR analysis clearly shows signals for the free ligand (besides the bowl), corresponding to one-third of the total amount. However, after addition of one-sixth more equivalent of $\left[\mathrm{Pd}\left(\mathrm{CH}_{3} \mathrm{CN}\right)_{4}\right]\left(\mathrm{BF}_{4}\right)_{2}$, the free ligand was completely consumed and the bowl species $c$ - $\mathbf{B}$ remained quantitatively (Figure S101). Diffusion of $\mathrm{Et}_{2} \mathrm{O}$ into a $\mathrm{CD}_{3} \mathrm{CN}$ solution of $\boldsymbol{c}-\mathbf{B}$ under strict exclusion of light gave a single crystal whose $\mathrm{X}$-ray diffraction analysis revealed the structure of cage $\left[\mathrm{Pd}_{2}(c-\right.$ $\left.\left.\mathbf{L}^{\mathrm{a}}\right)_{4}\right]\left(\mathrm{BF}_{4}\right)_{4}(c-\mathbf{C})$ rather than the expected bowl $c$-B. While seemingly surprising, this result agrees with previous findings from our group, where quinoline donor groups were shown to lead to $\left[\mathrm{Pd}_{2} \mathrm{~L}_{3}\right]$ bowls in solution but $\left[\mathrm{Pd}_{2} \mathrm{~L}_{4}\right]$ cages in the solid state. ${ }^{12 a}$ Gas-phase DFT studies indicate that energies for the formal cage/bowl transformation do not depend significantly on the photoisomeric state, further corroborating a fine energetic balance between solution and solid-state behavior (Figure S60). The compound crystallizes in the $P 4_{2} / \mathrm{mcm}$ 
a)

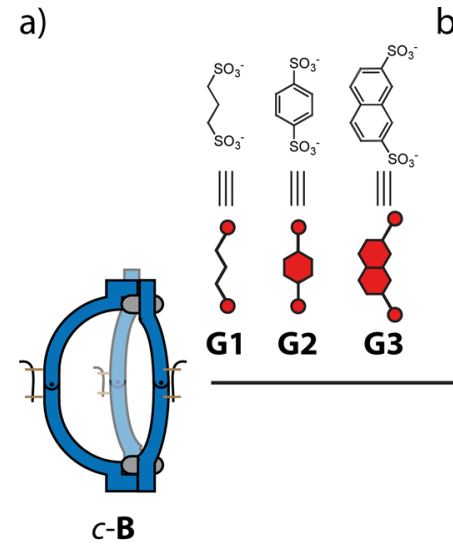

b)

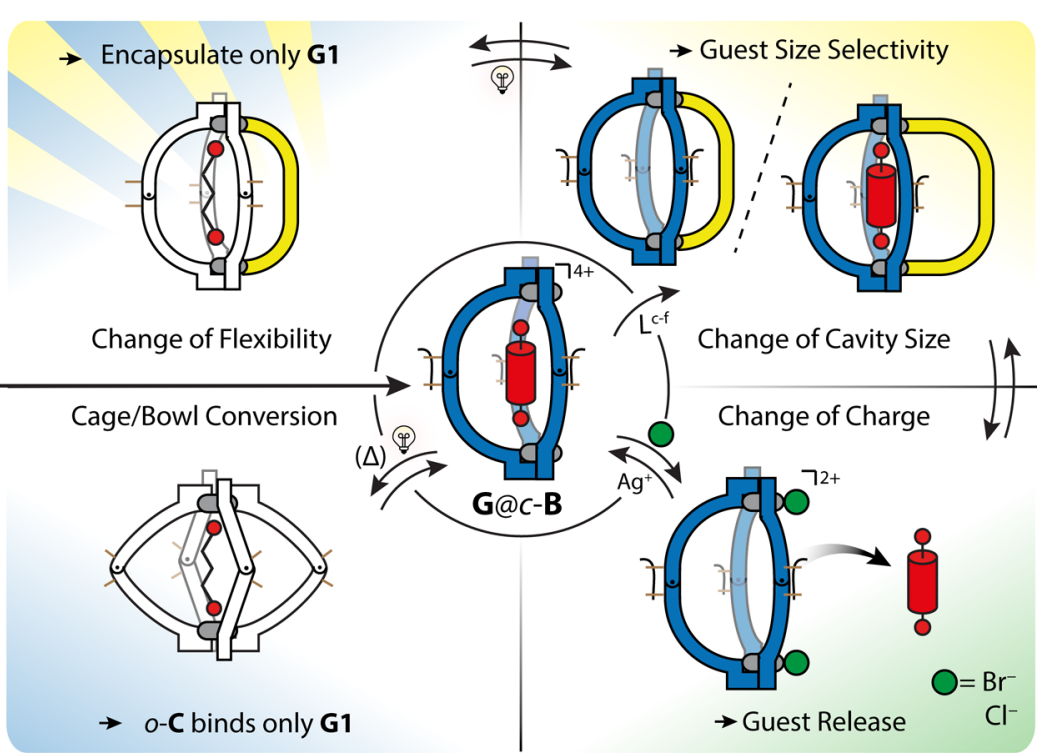

Figure 4. (a) c-B binds a series of guests to form a G@c-B host-guest system. (b) Stimuli response of G@c-B. Blue panel: light irradiation makes it possible to form $o-\mathrm{C}$ that binds only G1. Green panel: halide coordination tunes the overall system charge, triggering guest release. Yellow panel: addition of a fourth ligand tunes the cavity size and the system's selectivity toward G1, G2, and G3. Blue/yellow panel: irradiation of $c$-B-L $\mathbf{L}^{\mathrm{c}-\mathrm{f}}$ heteroleptic cages opens the photoswitches and increases the structural flexibility, modulating guest uptake selectivity and system stability.

space group, and the asymmetric unit contains both possible enantiomers with 50:50 occupancy. The crystal structure further showed that all ligands $c-\mathbf{L}^{\mathrm{a}}$ are arranged without any twisting with respect to the $\mathrm{Pd}-\mathrm{Pd}$ axis (Figure $3 \mathrm{~b}$; further details in the Supporting Information).

Homoleptic Cages: Photoswitching and Host-Guest Behavior. Irradiation of $o-C$ under UV light $(313 \mathrm{~nm})$ led to the formation of bowl $\boldsymbol{c}$-B, accompanied by the release of free ligand $c-\mathbf{L}^{\mathbf{a}}$, as observed by ${ }^{1} \mathrm{H}$ NMR analysis (Figure S102). Addition of $\mathrm{Pd}^{\mathrm{II}}$ cations ( 0.17 equiv) and further heating at 70 ${ }^{\circ} \mathrm{C}$ for $1 \mathrm{~h}$ made it possible to convert the excess free ligand $c$ $\mathbf{L}^{\mathbf{a}}$ into $\boldsymbol{c}$-B quantitatively. The obtained broad ${ }^{1} \mathrm{H}$ NMR spectrum indicated that $\boldsymbol{c}$-B was formed as a mixture of diastereomers. Vice versa, irradiation of $c$ - $\mathbf{B}$ at room temperature with $617 \mathrm{~nm}$ light resulted in a broad ${ }^{1} \mathrm{H}$ NMR spectrum, not showing any signs of free ligand (Figure S102). HR-ESI and even cold-spray ionization (CSI) mass spectrometry ( -30 ${ }^{\circ} \mathrm{C}$ ) could not detect any peaks related to a tentative $o$-B species. However, a low-temperature $\left(-35{ }^{\circ} \mathrm{C}\right){ }^{1} \mathrm{H}$ NMR measurement resulted in much sharper signals, allowing us to identify $\boldsymbol{o}$-B (Figure S108). Heating this $\boldsymbol{o}$-B solution for $1 \mathrm{~h}$ accelerates complete reassembly to the thermodynamic product $o-\mathbf{C}$ (Figure S102; 0.33 equiv of $o-\mathbf{L}^{\mathrm{a}}$ can be added to account for the change in stoichiometry). UV-vis analysis of ligand and cage samples corroborated quantitative switching fidelity in both cases, with the ligand showing faster photoisomerization as the cage, in accordance with our previous results for related systems (Figures S122-S124). ${ }^{22}$ Cage-bowl interconversion was studied over 10 cycles, showing very good fatigue resistance (Figure S125).

This photo-controlled reversible interconversion between cage and bowl makes it possible to tune the size and accessibility of the inner cavity. Therefore, size-dependent guest encapsulation of $o-\mathbf{C}$ and $c$ - $\mathbf{B}$ was investigated. To do this, we performed ${ }^{1} \mathrm{H}$ NMR titrations with three different anionic bis-sulfonate guests, $\mathbf{G 1 - G 3}$ (with $\mathrm{NBu}_{4}{ }^{+}$as counterion) (Figure 4a). Stepwise addition of the smallest guest, G1 (propane-1,3-bis-sulfonate), into a $\mathrm{CD}_{3} \mathrm{CN}$ solution of $o$-C led to the appearance of a new set of sharp ${ }^{1} \mathrm{H}$ NMR signals and significant downfield shifts of the signals assigned to inwardpointing protons $\left(\mathrm{H}_{\mathrm{a}}, \Delta \delta=0.67\right)$. This indicated encapsulation and slow exchange of guest G1 (Figure $4 \mathrm{~b}$, blue panel, Figure S61). The formation of host-guest complex [G1@oC] ${ }^{2+}$ was further confirmed by HR-ESI-MS spectrometry (Figure S62). For the slightly larger guests G2 (benzene-1,4bis-sulfonate) and G3 (naphthalene-2,7-bis-sulfonate), however, no encapsulation into $o-\mathbf{C}$ could be detected (Figures S63 and S64). On the contrary, due to its more open cavity, $c$-B was indeed found to be able to bind all three guest molecules, G1, G2, and G3, as confirmed by NMR spectroscopy and HRESI-MS (Figures S65-S70). To better evaluate the ${ }^{1} \mathrm{H}$ NMR signal shifting, enantiopure $S$-c-B was used in the experiments. After stepwise titration with G1, two new signals arose around $\delta=11.0 \mathrm{ppm}$, showing the formation of a new species in solution. Observation of a large peak assignable to $[\mathbf{G 1} @ c-B]^{2+}$ in the HR-ESI-MS spectrum further indicated binding with a 1:1 stoichiometry (Figure S66). After the addition of 3.0 equiv of the guest, a crystal suitable for single-crystal X-ray diffraction was obtained by leaving the sample overnight. Pleasingly, X-ray analysis confirmed the assumed structure of [G1@c-B], where guest $\mathbf{G 1}$ is accommodated in the concave well of the bowl between the two Pd atoms (Figure 3c). Titration of $S-c-B$ with G2 and G3 also resulted in encapsulation with a 1:1 stoichiometry, as confirmed by ${ }^{1} \mathrm{H}$ NMR experiments and HR-ESI-MS spectrometry (Figures S67-S70). Unfortunately, determination of association constants for the host-guest complexes from ${ }^{1} \mathrm{H}$ NMR titration data was not possible due to an onset of precipitation during the experiments. Notably, the stable interaction of $\mathbf{G} 2$ with bowl-shaped c-B inspired us to exploit this host-guest interaction with the kinetic photoswitch product $o-B$ at room temperature. After the addition of 1.0 equiv of $\mathbf{G} 2$ into a freshly prepared solution of $o$-B, ${ }^{1} \mathrm{H}$ NMR signals sharpened, allowing the characterization of the assembly (Figures S103-S106). HR-ESI-MS further supported the formation of host-guest complex G2@o-B, showing a single peak assigned to $\left[\mathbf{G} 2 @ \mathrm{Pd}_{2}\left(o-\mathbf{L}^{\mathbf{a}}\right)_{3}\right]^{2+}$ (Figure 
S107). Moreover, G2@o-B and G2@c-B could be reversibly interconverted by irradiation with UV light $(313 \mathrm{~nm})$ and red light $(617 \mathrm{~nm})$, respectively, as verified by ${ }^{1} \mathrm{H}$ NMR spectroscopy (Figure S103).

Heteroleptic Cages: Self-Assembly, Guest Binding, and Response to Chemical Stimuli. In bowl species such as $c$-B, each $\mathrm{Pd}^{\mathrm{II}}$ center is coordinated by three quinoline-based ligands, while the fourth coordination site is occupied by a solvent molecule (here acetonitrile or $\mathrm{H}_{2} \mathrm{O}$ ) to complement the square-planar coordination sphere. ${ }^{12}$ This encouraged us to synthesize a new series of banana-shaped bis-pyridine ligands $\left(\mathbf{L}^{\mathrm{c}-\mathrm{f}}\right.$, Figure $1 \mathrm{~b}$ ), having a length similar to that of $\mathbf{L}^{\mathrm{a}}$ (in terms of their $\mathrm{N} \cdots \mathrm{N}$ distances). While the pyridine group is a stronger donor as compared to the solvent used, it is also less sterically demanding than the quinoline donors on the other ligands, thus allowing it to replace the coordinated solvent as a fourth ligand, leading to the formation of unprecedented $\left[\mathrm{Pd}_{2} \mathrm{~L}_{3}^{\mathrm{A}} \mathrm{L}^{\mathrm{B}}\right]$ heteroleptic cages with a 3:1 ligand stoichiometry (Figure 1a, yellow panel). Consequently, addition of 1.0 equiv of the ligands to $\boldsymbol{c}-\mathbf{B}$ results in the formation of four heteroleptic cages with the general formula $\left[\mathrm{Pd}_{2}\left(c-\mathrm{L}^{\mathrm{a}}\right)_{3} \mathrm{~L}^{\mathrm{c}-\mathrm{f}}\right]^{-}$ $\left(\mathrm{BF}_{4}\right)_{4}\left(c-\mathbf{B}-\mathrm{L}^{\mathrm{c}-\mathrm{f}}\right)$, which were fully characterized by NMR techniques and HR-ESI-MS (Figure 5, Figures S26-S51).
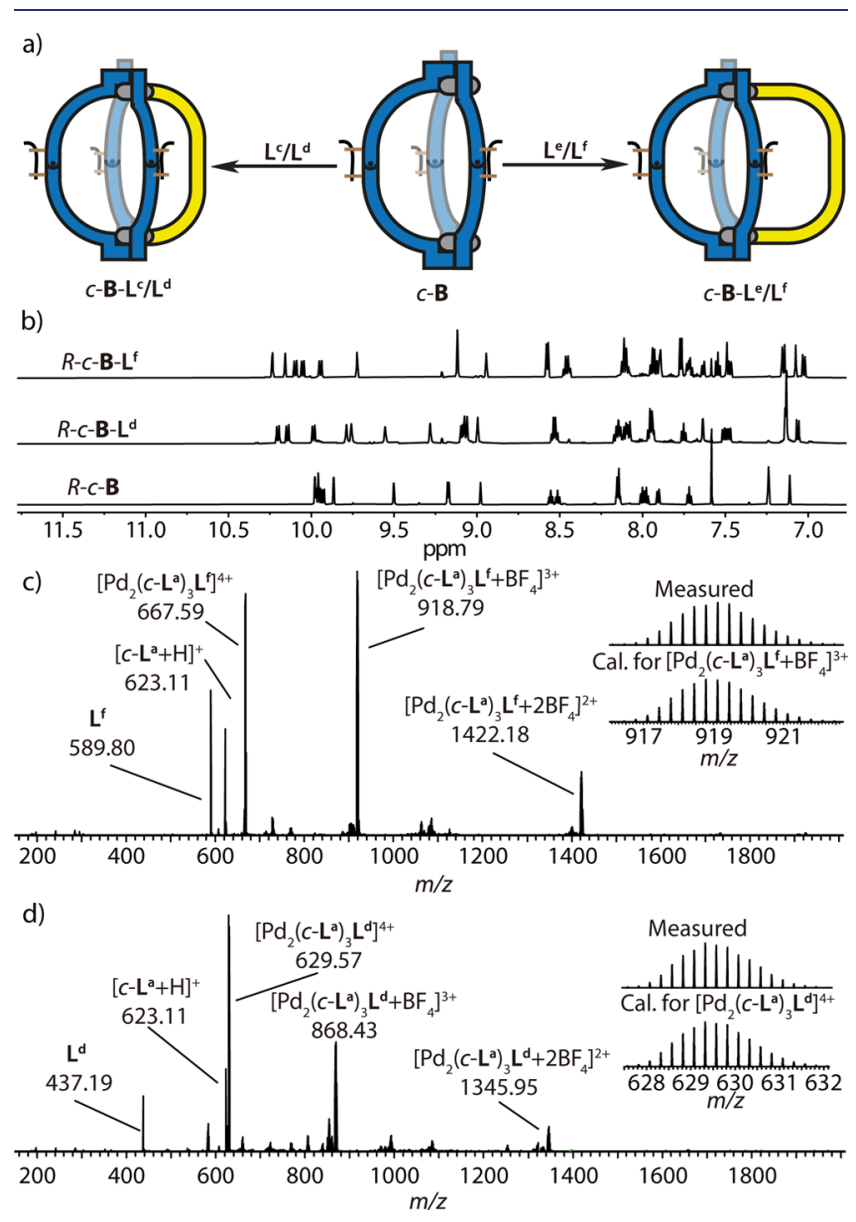

Figure 5. (a) Assembly of $\left[\mathrm{Pd}_{2} \mathrm{~L}_{3}^{\mathrm{A}} \mathrm{L}^{\mathrm{B}}\right]$ heteroleptic cages: addition of short-armed ligands $\mathbf{L}^{\mathbf{C}} / \mathbf{L}^{\mathrm{d}}$ (left) or long-armed ligands $\mathbf{L}^{\mathrm{e}} / \mathbf{L}^{\mathrm{f}}$ (right) to $c-B$ leads to the synthesis of cages $c-B-L^{c-f}$. (b) ${ }^{1} \mathrm{H}$ NMR spectra $\left(500 \mathrm{MHz}, \mathrm{CD}_{3} \mathrm{CN}, 298 \mathrm{~K}\right.$ ) of homochiral $R-c-\mathbf{B}, R-c-\mathbf{B}-\mathbf{L}^{\mathrm{d}}$, and $R-c-$ B-L $\mathbf{f}$. (c) ESI-MS spectrum of $c-\mathbf{B}-\mathbf{L}$, with isotope pattern of $\left[\operatorname{Pd}_{2}(c-\right.$ $\left.\left.\mathbf{L}^{\mathrm{a}}\right)_{3} \mathbf{L}^{\mathrm{f}}+\mathrm{BF}_{4}\right]^{3+}$ shown in the inset. (d) ESI-MS spectrum $c-\mathbf{B}-\mathbf{L}^{\mathrm{d}}$, with isotope pattern of $\left[\mathrm{Pd}_{2}\left(c-\mathbf{L}^{\mathbf{a}}\right)_{3} \mathbf{L}^{\mathbf{f}}\right]^{4+}$.
Again, enantiopure $R / S-c-B$ was used in order to obtain better resolved ${ }^{1} \mathrm{H}$ NMR spectra. Taking $c-\mathbf{B}-\mathbf{L}^{\mathrm{d}}$ as an example, reaction of $\mathbf{L}^{\mathbf{d}}$ with $c-\mathbf{B}$ resulted in the transformation of the ${ }^{1} \mathrm{H}$ NMR spectrum in which neither signals of the parental bowl species nor the free ligand $\mathbf{L}^{\mathrm{d}}$ are present (Figure $5 \mathrm{~b}$ ). HR-ESIMS (Figure 5d) clearly identified peaks corresponding to $\left[\mathrm{Pd}_{2}\left(c-\mathbf{L}^{\mathbf{a}}\right)_{3} \mathbf{L}^{\mathbf{d}}+n \mathrm{BF}_{4}\right]^{(4-n)+}(n=0-2)$. Moreover, a recorded ${ }^{1} \mathrm{H}$ DOSY spectrum confirmed the clear formation of one single species (Figure S35). It is worth noting that, to the best of our knowledge, this is the first example of a non-statistical self-assembly of $\mathrm{a}\left[\mathrm{Pd}_{2} \mathrm{~L}_{3}^{\mathrm{A}} \mathrm{L}^{\mathrm{B}}\right]$ heteroleptic cage. In addition, we explored the possibility of using also the photoisomeric $o-\mathbf{B}$ as a platform for the formation of heteroleptic cages. For this purpose, $\mathbf{L}^{\mathbf{d}}$ and $\mathbf{L}^{\mathbf{f}}$ were tested as fourth ligands. After addition of 1.0 equiv of the respective ligand to a solution of $o-\mathbf{B}$ at room temperature, ${ }^{1} \mathrm{H}$ NMR spectra of the resulting compounds were found to suffer from signal broadening, pointing at a highly dynamic behavior of the system. Interestingly, NMR signals turned sharp, allowing clear assignment, after guest G1 was added and apparently encapsulated (Figure 4b, blue/yellow panel, Figures S46 and S50). HR-ESI-MS spectra revealed prominent peaks consistent with the formula $\left[\mathrm{Pd}_{2}\left(o-\mathbf{L}^{\mathrm{a}}\right)_{3} \mathrm{~L}^{\mathrm{d}, \mathrm{f}}\left(\mathrm{BF}_{4}\right)_{n}\right]^{(4-n)+}(n=1-2)$, even in the absence of the guest, suggesting that the formation of heteroleptic cages $o-\mathbf{B}-\mathbf{L}^{\mathrm{d}, \mathrm{f}}$ from $\boldsymbol{o}-\mathbf{B}$ and $\mathbf{L}^{\mathrm{d}}$ or $\mathbf{L}^{\mathrm{f}}$ proceeds smoothly, despite the difficult-to-analyze NMR spectra (Figures S49 and S51).

Next, we investigated light-triggered switching between the two photoisomeric heteroleptic assemblies, $o-\mathbf{B}-\mathbf{L}^{\mathrm{d}}$ and $c-\mathbf{B}-\mathbf{L}^{\mathrm{d}}$ (Figure S111). Irradiation of $c-B-L^{d}$ under $617 \mathrm{~nm}$ light led to the same ${ }^{1} \mathrm{H}$ NMR spectrum as obtained for the self-assembly of $o$-B- $\mathbf{L}^{\mathrm{d}}$ from $o-\mathbf{B}$ and $\mathbf{L}^{\mathrm{d}}$. Conversely, irradiation of cage $o$-B$\mathbf{L}^{\mathrm{d}}$ with light of $313 \mathrm{~nm}$ wavelength restored the original ${ }^{1} \mathrm{H}$ NMR spectrum, showing full reversibility between the closed and open heteroleptic cages. Despite numerous attempts, we were not able to obtain single crystals suitable for X-ray analysis for any of the guest-free heteroleptic cages. To help understanding their structural features, we performed DFT $(\omega \mathrm{B} 97 \mathrm{XD} / \mathrm{LanL} 2 \mathrm{DZ})$ geometry optimizations (Figure 6a, Figure S59). The models reveal a notable enlargement of the cavity volume for $c-\mathbf{B}-\mathbf{L}^{\mathbf{f}}$ as compared to $c-\mathbf{B}-\mathbf{L}^{\mathrm{d}}$. We therefore assumed that this should lead to a distinguishable guest uptake behavior.

As described above, the interaction of the three guest molecules, G1, G2, and G3, with these heteroleptic cages was characterized by means of ${ }^{1} \mathrm{H}$ NMR titration experiments. The addition of $\mathbf{G} \mathbf{1}$ to the smaller cage $c-\mathbf{B}-\mathbf{L}^{\mathrm{d}}$ resulted in shifting of proton signals of $\mathrm{H}_{\mathrm{b}}$ and $\mathrm{H}_{\mathrm{b}^{\prime}}$, pointing outside from the cage cavity, while the inward-looking protons did not experience any shifting (Figure 6b). Furthermore, ESI-MS analysis only indicates unspecific association with the anionic guest (Figure 6d). The same result was obtained using G2 and G3, suggesting for all three guests merely interaction via the outside of the cage structure (Figures S77-S79). It is worth emphasizing that, as shown above, bowl $c$-B is able to bind all three guest molecules, while heteroleptic cage $c-\mathbf{B}-\mathbf{L}^{\mathrm{d}}$ does not. On the other hand, all three guests could be encapsulated inside cage $c$-B-L $\mathbf{L}^{\mathrm{f}}$ (Figure $4 \mathrm{~b}$, yellow panel). Hence, the larger fourth ligand $\mathbf{L}^{\mathrm{f}}$ (carrying phenylene spacers between backbone and coordinating pyridines as opposed to smaller $\mathbf{L}^{\mathbf{d}}$ ) allows the inner cavity to be sufficiently large to bind guest molecules, as confirmed by ${ }^{1} \mathrm{H}$ NMR and HR-ESI-MS experiments (Figure $6 \mathrm{~b}, \mathrm{c}$ ). After addition of $\mathbf{G 1}$ into a solution of $c-\mathbf{B}-\mathbf{L}$, a 

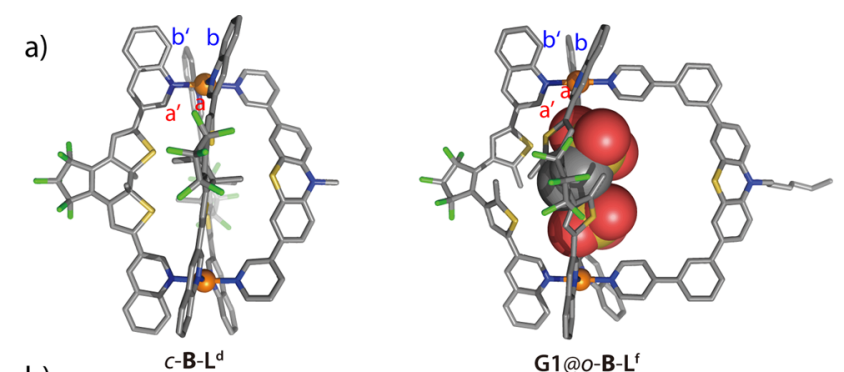

b)
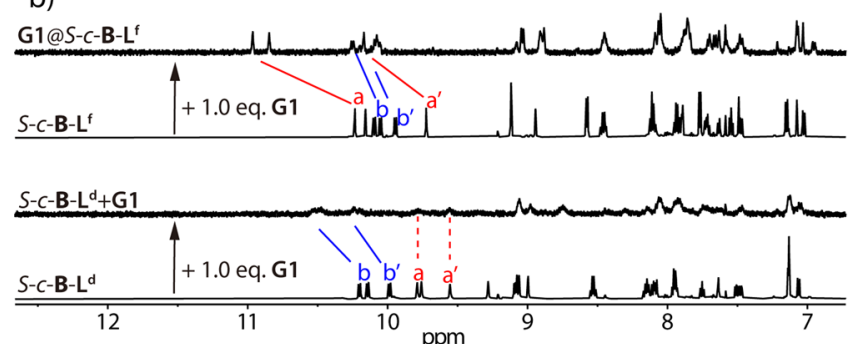

c)
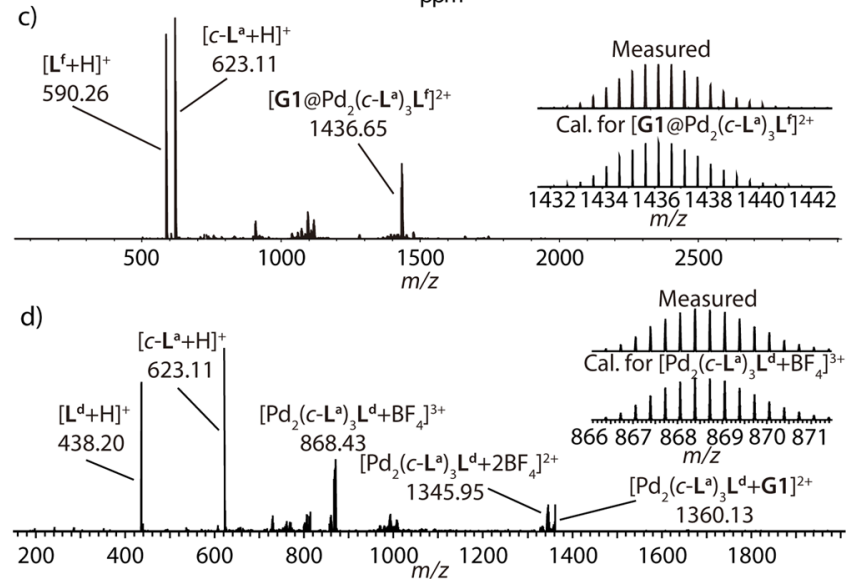

Figure 6. (a) DFT-optimized structure of $c-B-L^{d}$ (left) and X-ray structure of G1@o-B-L $\mathbf{L}^{\mathrm{f}}$ (right). (b) ${ }^{1} \mathrm{H}$ NMR spectra $(500 \mathrm{MHz}$, $\left.\mathrm{CD}_{3} \mathrm{CN}, 298 \mathrm{~K}\right)$ of homochiral $S-c-\mathbf{B}-\mathbf{L}^{\mathrm{d}}$ and $S-c-\mathbf{B}-\mathbf{L}$, and their corresponding spectra after addition of 1.0 equiv of G1. (c, d) ESI-MS spectra of (c) G1@o-B-L $\mathbf{L}^{\mathrm{f}}$, with isotope pattern of $\left[\mathbf{G} \mathbf{1} @ \mathrm{Pd}_{2}(c-\right.$ $\left.\left.\mathbf{L}^{\mathrm{a}}\right)_{3} \mathbf{L}^{\mathrm{f}}\right]^{2+}$ shown in the inset, and (d) $c-\mathbf{B}-\mathbf{L}^{\mathrm{d}}$ after addition of 1.0 equiv of $\mathbf{G 1}$, with isotope pattern of $\left[\mathrm{Pd}_{2}\left(c-\mathbf{L}^{\mathrm{a}}\right)_{3} \mathbf{L}^{\mathrm{d}}+\mathrm{BF}_{4}\right]^{3+}$.

new set of ${ }^{1} \mathrm{H}$ NMR signals appeared (Figure $6 \mathrm{~b}$ ). Further confirmation came from ESI-MS, where a peak assigned to $\left[\mathbf{G 1} @ c-B-L^{\mathrm{f}}\right]^{2+}$ was clearly detected (Figure 6c), indicating a 1:1 host-guest stoichiometry. Also, NMR titrations with G2 and G3 show shifting of the inward-pointing protons $\mathrm{H}_{\mathrm{a}}$ and $\mathrm{H}_{\mathrm{a}^{\prime}}$ until 1.0 equiv of the guest was added (Figures S82 and S84). Addition of more guest equivalents led to interaction with the cage's outer side, as confirmed by shifting of the signals of outward-pointing protons $\mathrm{H}_{\mathrm{b}}$ and $\mathrm{H}_{\mathrm{b}^{\prime}}$, followed by precipitation of the sample. The formation and stoichiometry of the host-guest complexes with G2 and G3 were further confirmed by ESI-MS (Figures S83 and S85). Finally, guest affinity was also investigated for cage $c-\mathbf{B}-\mathbf{L}^{\mathrm{e}}$, leading to results comparable to those obtained for $\boldsymbol{c}-\mathbf{B}-\mathbf{L}^{\mathbf{f}}$ (Figures S86-S91).

Interestingly, the host-guest behavior of the $o-\mathbf{B}-\mathbf{L}$ cages is different from that of the analogous assemblies with the closedform DTE photoswitch, presumably due to the higher flexibility of the backbone in its open photoisomeric form. Thus, addition of $\mathbf{G} \mathbf{1}$ to the small-cavity cage $o-\mathbf{B}-\mathbf{L}^{\mathrm{d}}$ led to the formation of a $\left[\mathbf{G 1} @ o-\mathbf{B}-\mathbf{L}^{\mathrm{d}}\right]$ host-guest compound. While the NMR spectrum of $o-\mathbf{B}-\mathbf{L}^{\mathrm{d}}$ is characterized by broad signals, stepwise titration with G1 led to a new set of sharp signals, showing at the same time guest uptake and stabilization of a more defined conformer of the host (Figure S92). This allowed a better characterization of the system with $2 \mathrm{D}$ NMR spectra (Figures S47 and S48), and therefore an indirect confirmation of the $o$-B-L ${ }^{\mathrm{d}}$ heteroleptic cage assembly. Further support came from ESI-MS analysis, with a prominent peak assigned to $\left[\mathbf{G} 1 @ o-\mathbf{B}-\mathbf{L}^{\mathrm{d}}\right]^{2+}$, confirming once more the binding of $\mathbf{G} \mathbf{1}$ with a 1:1 stoichiometry (Figure S93). Photoswitching of G1@o-B$\mathbf{L}^{\mathrm{d}}$ triggers guest release to give $c-\mathbf{B}-\mathbf{L}^{\mathrm{d}}$, for which NMR results indicate only outside guest interaction (Figure S113 compared to Figure S77). Titration of $o-\mathbf{B}-\mathbf{L}^{\mathrm{d}}$ with the bigger guests G2 and $\mathbf{G} 3$ showed no signs of encapsulation, comparable to the closed-ligand cage analogue (Figures S94 and S95). On the other hand, when using heteroleptic cage derivative $o-\mathbf{B}-\mathbf{L}_{\text {, }}$, again possessing a larger cavity size, uptake of guest G1 was certainly anticipated and indeed confirmed by ${ }^{1} \mathrm{H}$ NMR titration and ESI-MS. As for the shorter analogue, the titration with G1 led to a new set of ${ }^{1} \mathrm{H}$ NMR signals, converting the broad signals of the empty cage into a better resolved NMR spectrum (Figure S96). HR-ESI-MS proved a 1:1 binding stoichiometry, showing only the peaks of $\left[\mathbf{G 1} @ o-\mathbf{B}-\mathbf{L}^{\mathrm{f}}\right]^{2+}$ (Figure S97). Addition of an excess of guest (3 equiv) led to precipitate formation, together with the growth of single crystals suitable for X-ray analysis (Figure 6a). The compound crystallizes in monoclinic space group $P 2_{1} / n$ and was confirmed to be G1@o-B-L $\mathbf{f}$. The structure clearly shows the formation of a $\left[\mathrm{Pd}_{2} \mathrm{~L}_{3}^{\mathrm{A}} \mathrm{L}^{\mathrm{B}}\right]$ heteroleptic cage consisting of three ligands $o-L^{a}$ and one ligand $L^{f}$, where the pyridines of $\mathbf{L}^{f}$ saturate the coordination spheres of the $\mathrm{Pd}^{\mathrm{II}}$ ions. $\mathrm{Gl}$ is found to sit inside the cavity, in full agreement with the NMR and MS data.

Unfortunately, experiments probing the uptake of the bigger guests $\mathbf{G} 2$ and $\mathbf{G} 3$ inside $o-\mathbf{B}-\mathbf{L}^{\mathrm{f}}$ were complicated by concomitant cage disassembly. Titration with G2 indeed showed the appearance of a new set of weak ${ }^{1} \mathrm{H}$ NMR signals, however, accompanied by release of free ligand $\mathbf{L}^{\mathrm{f}}$ (Figure S98), suggesting partial decomposition of the cage. Titration with $\mathbf{G} 3$ led to decomposition of $o-\mathbf{B}-\mathbf{L}^{\mathrm{f}}$ right from the beginning of the guest addition (Figure S100).

Finally, we explored the possibility to use halide anions as an external stimulus and competitor, either to the solvent molecules or to the pyridine-based ligands occupying the fourth $\mathrm{Pd}^{\mathrm{II}}$ coordination sites (Figure 1a, green panel). Following this assumption, 2.0 equiv of $\mathrm{Cl}^{-}$or $\mathrm{Br}^{-}\left(\mathrm{NBu}_{4}^{+}\right.$ as countercation) was added to a $c$-B solution. The clean formation of $\left[\mathrm{Pd}_{2}\left(c-\mathbf{L}^{\mathrm{a}}\right)_{3}(\mathrm{Cl} / \mathrm{Br})_{2}\right]\left(\mathrm{BF}_{4}\right)_{2} \quad(c-\mathbf{B}-\mathbf{C l} / \mathbf{B r})$ was confirmed by a combination of NMR and HR-ESI-MS experiments (Figures S18-S25). Interestingly, this stimulus could be reversed by addition of $\mathrm{a} \mathrm{Ag}^{+}$salt $\left(\mathrm{AgBF}_{4}\right)$, leading to recovery of the initial bowl compound (Figure S115). Hence, the two species can reversibly interconvert under chemical control: the addition and removal of halide ions trigger the formation of either $c-\mathbf{B}-\mathbf{C l} / \mathbf{B r}$ or $c-\mathbf{B}$, respectively. The same concept can be applied to the host-guest complexes $\mathbf{G} @ c-\mathbf{B}$. As coordination of the halide anions affects the overall charge of the supramolecular compound, going from a +4 charged species to $a+2$ cationic assembly, the induction of guest release was the consequence (Figure $4 \mathrm{~b}$, green panel). For example, addition of 2 equiv of $\mathrm{Br}^{-}$to a solution of enantiomerically pure G2@R-c-B forms the species $R-c-\mathbf{B}-\mathbf{B r}$ and triggers release of the guest from the bowl's pocket, as confirmed by ${ }^{1} \mathrm{H}$ NMR spectroscopy. Again, this process is reversible: addition of $\mathrm{Ag}^{+}$ 
cations led to precipitation of $\mathrm{AgBr}$ salt and restoration of the G2@R-c-B host-guest compound, as confirmed by ${ }^{1} \mathrm{H}$ NMR spectroscopy (Figure S117). Subsequently, we applied this approach to the heteroleptic cages $\left[\mathrm{Pd}_{2} \mathrm{~L}_{3}^{\mathrm{A}} \mathrm{L}^{\mathrm{B}}\right]$ and corresponding host-guest compounds. Rewardingly, a reversible structural conversion between the heteroleptic cages and $c$-B$\mathrm{Br}$ bowl is achieved by addition of bromide and silver ions (Figure 1a, yellow and green panels). Taking $c-B-L^{e}$ as an example, the cage was disassembled after addition of 2.0 equiv of $\mathrm{Br}^{-}$into a $c-\mathbf{B}-\mathrm{L}^{\mathrm{e}}$ solution, as clearly seen from ${ }^{1} \mathrm{H}$ NMR spectra (Figure S118), giving rise to $\mathbf{c}-\mathbf{B}-\mathbf{B r}$ and releasing free $\mathbf{L}^{\mathbf{e}}$ at the same time. In this case, a stoichiometric amount of $\mathrm{Ag}^{+}$(2.0 equiv) was not enough to restore the starting heteroleptic cage. However, adding an excess amount of silver salt (up to 10 equiv) into the mixture at room temperature allowed us to reassemble cage $c-\mathbf{B}-\mathbf{L}^{\mathrm{e}}$. This approach can be extended to an even more complex system, where four components $\left(\mathrm{Pd}^{\mathrm{II}}, \mathbf{L}^{\mathrm{a}}, \mathbf{L}^{\mathrm{e}}, \mathbf{G} \mathbf{1}\right)$ are assembled through integrative self-sorting to give the host-guest system G1@cB- $\mathrm{L}^{\mathrm{e}}$. Herein, the combination of guest uptake properties and chemical stimuli led to a reversible on/off guest binding event (Figure 7a). Upon addition of 2.0 equiv of $\mathrm{Br}^{-}$to a $\mathbf{G 1} @ c-\mathbf{B}-\mathrm{L}^{\mathrm{e}}$

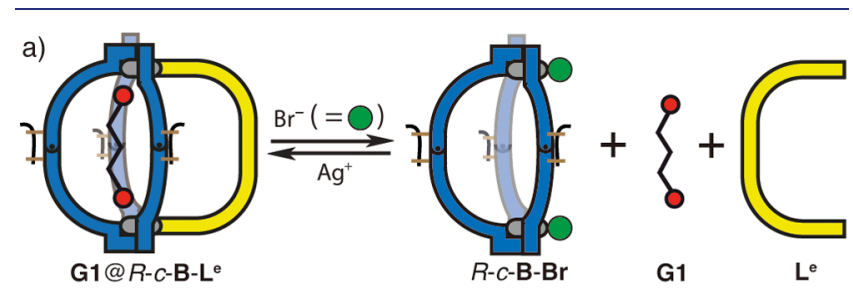

b)

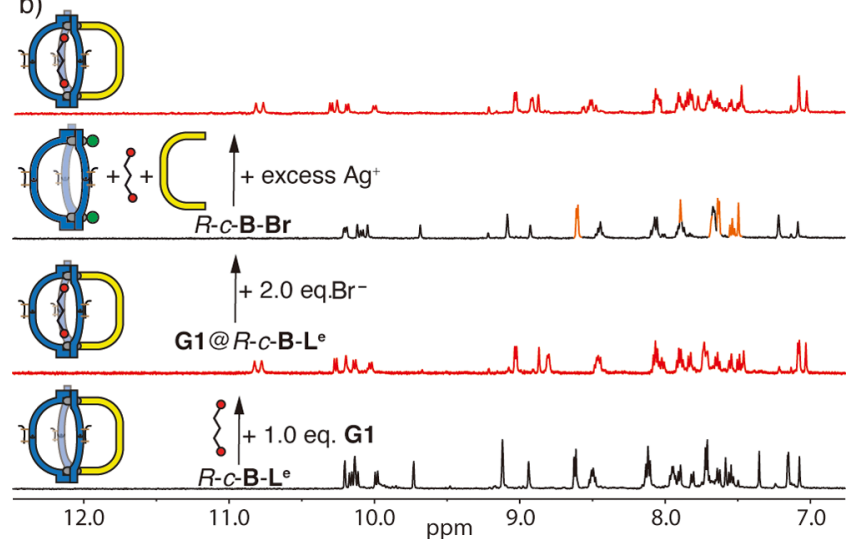

Figure 7. (a) Scheme and (b) ${ }^{1} \mathrm{H}$ NMR spectra $\left(500 \mathrm{MHz}, \mathrm{CD}_{3} \mathrm{CN}\right.$, $298 \mathrm{~K}$ ) showing how addition of $\mathrm{Br}^{-} / \mathrm{Ag}^{+}$triggers the reversible release and binding of $\mathbf{G 1}$ from the heteroleptic cage. The ${ }^{1} \mathrm{H}$ NMR spectra show, from bottom to top: $R-c-B-L^{\mathrm{e}}$; addition of 1.0 equiv of G1, resulting in G1@R-c-B-L $\mathbf{L}^{\mathbf{e}}$ (red marked); addition of 2.0 equiv of $\mathrm{Br}^{-}$, releasing "free" ligand $\mathbf{L}^{\mathrm{e}}$ (orange signals) and $\mathbf{G} 1$ simultaneously, thus forming $R-c-B-B r$; and addition of an excess of $\mathrm{Ag}^{+}$(up to 20 equiv), removing the halide anions and restoring the heteroleptic host-guest complex G1@R-c-B-L ${ }^{\mathbf{e}}$.

solution, the ${ }^{1} \mathrm{H}$ NMR spectra showed the complete release of G1 and the decomplexation of ligand $\mathbf{L}^{\mathrm{e}}$, together with the formation of $c-\mathbf{B}-\mathbf{B r}$ (Figure $7 \mathrm{~b}$ ). Subsequently, addition of an excess of $\mathrm{Ag}^{+}$allows the complex mixture to reassemble, forming selectively only the host-guest complex G1@c-B-L $\mathbf{L}^{\mathbf{e}}$ following a non-statistical integrative self-sorting process (Figure 7b).

\section{CONCLUSIONS}

In summary, the appropriate design of a photochromic ditopic banana-shaped DTE-based ligand, $\mathbf{L}^{\mathbf{a}}$, carrying bulky quinoline donor groups, allowed us to combine light-switchable backbone flexibility with steric hindrance around a $\mathrm{Pd}^{\mathrm{II}}$ coordination center, leading to a multi-stimuli-responsive system. Self-assembly of $\mathbf{L}^{\mathbf{a}}$ photoisomers with $\mathrm{Pd}^{\mathrm{II}}$ ions leads to the controlled formation of a coordination cage, $o-\mathbf{C}$, or a bowl-shaped object, $c$-B, reversibly interconvertible by irradiation with light of different wavelengths. Their structural diversity results in a different guest binding behavior: compared to the small pocket of cage $o-\mathbf{C}$, bowl $c$-B has a larger cavity for guest uptake. Moreover, the bowl structure can act as platform to form an unprecedented type of $\left[\mathrm{Pd}_{2} \mathrm{~L}_{3}^{\mathrm{A}} \mathrm{L}^{\mathrm{B}}\right]$ heteroleptic cages in a non-statistical way. Proper design of the fourth ligand, alone or in combination with the light stimulus, allowed us to further tune the guest binding affinity. Finally, the addition of halide and silver ions led to a reversible, chargemodulating stimulus to trigger on/off guest binding. Herein, we report a new strategy to form heteroleptic, multi-functional cages, where the host-guest properties derive from the synergy of all contained building blocks: a photochromic ligand backbone, a quinoline-based, congested coordination environment, and a fourth ligand coming in different sizes. This generates a multi-stimuli-responsive system where light, halides, and additional ligands act either individually or in a cooperative fashion.

\section{ASSOCIATED CONTENT}

\section{Supporting Information}

The Supporting Information is available free of charge at https://pubs.acs.org/doi/10.1021/jacs.0c12188.

Synthetic procedures, NMR, MS, X-ray, further spectroscopic data, and DFT calculation results, including Schemes S1-S14, Figures S1-S125, and Tables S1-S4 (PDF)

\section{Accession Codes}

CCDC 2003429-2003433 contain the supplementary crystallographic data for this paper. These data can be obtained free of charge via www.ccdc.cam.ac.uk/data_request/cif, or by emailing data request@ccdc.cam.ac.uk, or by contacting The Cambridge Crystallographic Data Centre, 12 Union Road, Cambridge CB2 1EZ, UK; fax: +44 1223336033.

\section{AUTHOR INFORMATION}

\section{Corresponding Author}

Guido H. Clever - Faculty of Chemistry \& Chemical Biology, TU Dortmund University, 44227 Dortmund, Germany; ○ orcid.org/0000-0001-8458-3060; Email: guido.clever@ tu-dortmund.de

\section{Authors}

Ru-Jin Li - Faculty of Chemistry \& Chemical Biology, TU Dortmund University, 44227 Dortmund, Germany

Jacopo Tessarolo - Faculty of Chemistry \& Chemical Biology, TU Dortmund University, 44227 Dortmund, Germany

Haeri Lee - Faculty of Chemistry \& Chemical Biology, TU Dortmund University, 44227 Dortmund, Germany

Complete contact information is available at:

https://pubs.acs.org/10.1021/jacs.0c12188 


\section{Author Contributions}

${ }^{\ddagger}$ R.-J.L. and J.T. contributed equally.

\section{Notes}

The authors declare no competing financial interest.

\section{ACKNOWLEDGMENTS}

This work was supported by the European Research Council (ERC Consolidator grant 683083, RAMSES). Diffraction data were collected at PETRA III at DESY, a member of the Helmholtz Association (HGF). The authors thank Dr. Julian J. Holstein for collecting and integrating the diffraction data and Dr. Anja Burkhardt for assistance in using synchrotron beamline P11 (I-20160736). We thank Christiane Heitbrink, Andreas Brockmeyer, Dr. Petra Janning (MPI Dortmund), and Laura Schneider for measuring mass spectra. We thank Prof. Joakim Andréasson, Chalmers University, Göteborg, for providing a sample of ligand $\mathbf{L}^{\mathrm{a}}$. This work was supported by a National Research Foundation of Korea grant funded by the Korean Government (NRF-2018R1A6A3A03012675).

\section{REFERENCES}

(1) (a) Wu, G.-Y.; Chen, L.-J.; Xu, L.; Zhao, X.-L.; Yang, H.-B. Construction of Supramolecular Hexagonal Metallacycles via Coordination-Driven Self-Assembly: Structure, Properties and Application. Coord. Chem. Rev. 2018, 369, 39-75. (b) Chen, L.-J.; Yang, H.-B.; Shionoya, M. Chiral Metallosupramolecular Architectures. Chem. Soc. Rev. 2017, 46, 2555-2576. (c) Yu, G.; Jie, K.; Huang, F. Supramolecular Amphiphiles Based on Host-Guest Molecular Recognition Motifs. Chem. Rev. 2015, 115, 7240-7303. (d) Kim, D. S.; Sessler, J. L. Calix[4]Pyrroles: Versatile Molecular Containers with Ion Transport, Recognition, and Molecular Switching Functions. Chem. Soc. Rev. 2015, 44, 532-546. (e) Cook, T. R.; Zheng, Y.-R.; Stang, P. J. Metal-Organic Frameworks and SelfAssembled Supramolecular Coordination Complexes: Comparing and Contrasting the Design, Synthesis, and Functionality of MetalOrganic Materials. Chem. Rev. 2013, 113, 734-777. (f) Lindoy, L. F.; Park, K.-M.; Lee, S. S. Metals, Macrocycles and Molecular Assemblies - Macrocyclic Complexes in Metallo-Supramolecular Chemistry. Chem. Soc. Rev. 2013, 42, 1713-1727. (g) Liu, Y.; Zhao, W.; Chen, C.-H.; Flood, A. H. Chloride capture using a $\mathrm{C}-\mathrm{H}$ hydrogen bonding cage. Science 2019, 365, 159-161. (h) Yoshizawa, M.; Catti, L. Bent Anthracene Dimers as Versatile Building Blocks for Supramolecular Capsules. Acc. Chem. Res. 2019, 52, 2392-2404.

(2) (a) Cook, T. R; Stang, P. J. Recent Developments in the Preparation and Chemistry of Metallacycles and Metallacages via Coordination. Chem. Rev. 2015, 115, 7001-7045. (b) Sun, Y.; Chen, C.; Stang, P. J. Soft Materials with Diverse Suprastructures via the Self-Assembly of Metal-Organic Complexes. Acc. Chem. Res. 2019, 52, 802-817. (c) Datta, S.; Saha, M. L.; Stang, P. J. Hierarchical Assemblies of Supramolecular Coordination Complexes. Acc. Chem. Res. 2018, 51, 2047-2063. (d) Yoshizawa, M.; Catti, L. Bent Anthracene Dimers as Versatile Building Blocks for Supramolecular Capsules. Acc. Chem. Res. 2019, 52, 2392-2404.

(3) (a) Wang, L.; Song, B.; Khalife, S.; Li, Y.; Ming, L.-J.; Bai, S.; Xu, Y.; Yu, H.; Wang, M.; Wang, H.; Li, X. Introducing Seven Transition Metal Ions into Terpyridine-Based Supramolecules: Self-Assembly and Dynamic Ligand Exchange Study. J. Am. Chem. Soc. 2020, 142, 1811-1821. (b) Sun, Q.-F.; Iwasa, J.; Ogawa, A.; Ishido, Y.; Sato, S.; Ozeki, T.; Sei, Y.; Yamaguchi, K.; Fujita, M. Self-Assembled M24L48 Polyhedra and Their Sharp Structural Switch upon Subtle Ligand Variation. Science 2010, 328, 1144-1147. (c) Han, M.; Engelhard, D. M.; Clever, G. H. Self-assembled coordination cages based on bananashaped ligands. Chem. Soc. Rev. 2014, 43, 1848-1860.

(4) (a) Yamashina, M.; Tanaka, Y.; Lavendomme, R.; Ronson, T. K.; Pittelkow, M.; Nitschke, J. R. An Antiaromatic-Walled Nanospace. Nature 2019, 574, 511-515. (b) Wei, S.; Pan, M.; Fan, Y.; Liu, H.; Zhang, J.; Su, C. Creating Coordination-Based Cavities in a
Multiresponsive Supramolecular Gel. Chem. - Eur. J. 2015, 21, 7418-7427. (c) Saha, S.; Holzapfel, B.; Chen, Y.-T.; Terlinden, K.; Lill, P.; Gatsogiannis, C.; Rehage, H.; Clever, G. H. Rational Design of an Amphiphilic Coordination Cage-Based Emulsifier. J. Am. Chem. Soc. 2018, 140, 17384-17388.

(5) (a) Rizzuto, F. J.; von Krbek, L. K. S.; Nitschke, J. R. Strategies for Binding Multiple Guests in Metal-Organic Cages. Nat. Rev. Chem. 2019, 3, 204-222. (b) Zarra, S.; Wood, D. M.; Roberts, D. A.; Nitschke, J. R. Molecular Containers in Complex Chemical Systems. Chem. Soc. Rev. 2015, 44, 419-432.

(6) (a) Leenders, S. H. A. M.; Gramage-Doria, R.; de Bruin, B.; Reek, J. N. H. Transition Metal Catalysis in Confined Spaces. Chem. Soc. Rev. 2015, 44, 433-448. (b) Kaphan, D. M.; Levin, M. D.; Bergman, R. G.; Raymond, K. N.; Toste, F. D. A Supramolecular Microenvironment Strategy for Transition Metal Catalysis. Science 2015, 350, 1235-1238. (c) Guo, J.; Fan, Y.; Lu, Y.; Zheng, S.; Su, C.Y. Visible-Light Photocatalysis of Asymmetric [2+2] Cycloaddition in Cage-Confined Nanospace Merging Chirality with Triplet-State Photosensitization. Angew. Chem., Int. Ed. 2020, 59, 8661-8669. (d) Yoshizawa, M.; Klosterman, J. K.; Fujita, M. Functional Molecular Flasks: New Properties and Reactions within Discrete, Self-Assembled Hosts. Angew. Chem., Int. Ed. 2009, 48, 3418-3438.

(7) (a) Rizzuto, F. J.; Kieffer, M.; Nitschke, J. R. Quantified Structural Speciation in Self-Sorted $\mathrm{Co}_{6}^{\mathrm{II}} \mathrm{L} 4$ Cage Systems. Chem. Sci. 2018, 9, 1925-1930. (b) Frank, M.; Ahrens, J.; Bejenke, I.; Krick, M.; Schwarzer, D.; Clever, G. H. Light-Induced Charge Separation in Densely Packed Donor-Acceptor Coordination Cages. J. Am. Chem. Soc. 2016, 138, 8279-8287. (c) Johnson, A. M.; Hooley, R. J. Steric Effects Control Self-Sorting in Self-Assembled Clusters. Inorg. Chem. 2011, 50, 4671-4673. (d) Ebbert, K. E.; Schneider, L.; Platzek, A.; Drechsler, C.; Chen, B.; Rudolf, R.; Clever, G. H. Resolution of Minor Size Differences in a Family of Heteroleptic Coordination Cages by Trapped Ion Mobility ESI-MS. Dalton. Trans. 2019, 48, 1107011075. (e) Ayme, J.-F.; Beves, J. E.; Campbell, C. J.; Leigh, D. A. Probing the Dynamics of the Imine-Based Pentafoil Knot and Pentameric Circular Helicate Assembly. J. Am. Chem. Soc. 2019, 141, 3605-3612.

(8) Yamashina, M.; Yuki, T.; Sei, Y.; Akita, M.; Yoshizawa, M. Anisotropic Expansion of an M2L4 Coordination Capsule: Host Capability and Frame Rearrangement. Chem. - Eur. J. 2015, 21, 42004204.

(9) Preston, D.; Barnsley, J. E.; Gordon, K. C.; Crowley, J. D. Controlled Formation of Heteroleptic $[\mathrm{Pd} 2(\mathrm{~L} \text { a }) 2(\mathrm{Lb}) 2]^{4+}$ Cages. J. Am. Chem. Soc. 2016, 138, 10578-10585.

(10) (a) Li, J.-R.; Zhou, H.-C. Bridging-ligand-substitution strategy for the preparation of metal-organic polyhedral. Nat. Chem. 2010, 2 , 893-898. (b) Sun, Q.-F.; Sato, S.; Fujita, M. An M12(L1)12(L2)12 Cantellated Tetrahedron: A Case Study on Mixed-Ligand SelfAssembly. Angew. Chem., Int. Ed. 2014, 53, 13510-13513. (c) Howlader, P.; Das, P.; Zangrando, E.; Mukherjee, P. S. UreaFunctionalized Self-Assembled Molecular Prism for Heterogeneous Catalysis in Water. J. Am. Chem. Soc. 2016, 138, 1668-1676. (d) Mukherjee, S.; Mukherjee, P. S. Template-free multicomponent coordination-driven self-assembly of $\mathrm{Pd}(\mathrm{ii}) / \mathrm{Pt}(\mathrm{ii})$ molecular cages. Chem. Commun. 2014, 50, 2239-2248. (e) Prusty, S.; Yazaki, K.; Yoshizawa, M.; Chand, D. K. A Truncated Molecular Star. Chem. Eur. J. 2017, 23, 12456-12461. (f) Samantray, S.; Krishnaswamy, S.; Chand, D. K. Self-assembled conjoined-cages. Nat. Commun. 2020, 11, 880-891. (g) Bloch, W. M.; Abe, Y.; Holstein, J. J.; Wandtke, C. M.; Dittrich, B.; Clever, G. H. Geometric Complementarity in Assembly and Guest Recognition of a Bent Heteroleptic Cis -[Pd2LA2LB2] Coordination Cage. J. Am. Chem. Soc. 2016, 138, 13750-13755. (h) Bloch, W. M.; Holstein, J. J.; Hiller, W.; Clever, G. H. Morphological Control of Heteroleptic Cis- and Trans-Pd2L2L'2 Cages. Angew. Chem., Int. Ed. 2017, 56, 8285-8289. (i) Wu, K.; Zhang, B.; Drechsler, C.; Holstein, J. J.; Clever, G. H. BackboneBridging Promotes Diversity in Heteroleptic Cages. Angew. Chem., Int. Ed. 2020, DOI: 10.1002/anie.202012425. 
(11) Zhu, R.; Bloch, W. M.; Holstein, J. J.; Mandal, S.; Schäfer, L.; Clever, G. H. Donor-Site-Directed Rational Assembly of Heteroleptic cis-[Pd2L2L2] Coordination Cages from Picolyl Ligands. Chem. - Eur. J. 2018, 24, 12976-12982.

(12) (a) Chen, B.; Holstein, J. J.; Horiuchi, S.; Hiller, W. G.; Clever, G. H. Pd(II) Coordination Sphere Engineering: Pyridine Cages, Quinoline Bowls, and Heteroleptic Pills Binding One or Two Fullerenes. J. Am. Chem. Soc. 2019, 141, 8907-8913. (b) Chen, B.; Horiuchi, S.; Holstein, J. J.; Tessarolo, J.; Clever, G. H. Tunable Fullerene Affinity of Cages, Bowls and Rings Assembled by PdII Coordination Sphere Engineering. Chem. - Eur. J. 2019, 25, 1492114927.

(13) (a) Bloch, W. M.; Clever, G. H. Integrative Self-Sorting of Coordination Cages Based on 'Naked' Metal Ions. Chem. Commun. 2017, 53, 8506-8516. (b) Pullen, S.; Clever, G. H. Mixed-Ligand Metal-Organic Frameworks and Heteroleptic Coordination Cages as Multifunctional Scaffolds-A Comparison. Acc. Chem. Res. 2018, 51, 3052-3064. (c) Bardhan, D.; Chand, D. K. Palladium(II)-Based SelfAssembled Heteroleptic Coordination Architectures: A Growing Family. Chem. - Eur. J. 2019, 25, 12241-12269.

(14) (a) Gu, Y.; Alt, E. A.; Wang, H.; Li, X.; Willard, A. P.; Johnson, J. A. Photoswitching Topology in Polymer Networks with MetalOrganic Cages as Crosslinks. Nature 2018, 560, 65-69. (b) Wang, W.; Wang, Y.-X.; Yang, H.-B. Supramolecular Transformations within Discrete Coordination-Driven Supramolecular Architectures. Chem. Soc. Rev. 2016, 45, 2656-2693. (c) Burke, M. J.; Nichol, G. S.; Lusby, P. J. Orthogonal Selection and Fixing of Coordination Self-Assembly Pathways for Robust Metallo-Organic Ensemble Construction. J. Am. Chem. Soc. 2016, 138, 9308-9315. (d) Tam, A. Y.-Y.; Yam, V. W.-W. Recent Advances in Metallogels. Chem. Soc. Rev. 2013, 42, 15401567.

(15) Kim, T. Y.; Vasdev, R. A. S.; Preston, D.; Crowley, J. D. Strategies for Reversible Guest Uptake and Release from Metallosupramolecular Architectures. Chem. - Eur. J. 2018, 24, 14878-14890.

(16) (a) Kishi, N.; Akita, M.; Yoshizawa, M. Selective Host-Guest Interactions of a Transformable Coordination Capsule/Tube with Fullerenes. Angew. Chem., Int. Ed. 2014, 53, 3604-3607. (b) Lewis, J. E. M.; Gavey, E. L.; Cameron, S. A.; Crowley, J. D. StimuliResponsive Pd2L4Metallosupramolecular Cages: Towards Targeted Cisplatin Drug Delivery. Chem. Sci. 2012, 3, 778-784. (c) Lisboa, L. S.; Findlay, J. A.; Wright, L. J.; Hartinger, C. G.; Crowley, J. D. A Reduced-Symmetry Heterobimetallic [PdPtL4] ${ }^{4+}$ Cage: Assembly, Guest Binding and Stimulus-induced Switching. Angew. Chem., Int. Ed. 2020, 59, 11101-11107.

(17) (a) Löffler, S.; Lübben, J.; Krause, L.; Stalke, D.; Dittrich, B.; Clever, G. H. Triggered Exchange of Anionic for Neutral Guests inside a Cationic Coordination Cage. J. Am. Chem. Soc. 2015, 137, 1060-1063. (b) Kolien, J.; Inglis, A. R.; Vasdev, R. A. S.; Howard, B. I.; Kruger, P. E.; Preston, D. Exploiting the Labile Site in Dinuclear $\left[\mathrm{Pd}_{2} \mathrm{~L}_{2}\right]^{\mathrm{n}+}$ Metallo-cycles: Multi-step Control Over Binding Affinity Without Alteration of Core Host Structure. Inorg. Chem. Front. 2020, 7, 3895-3908.

(18) (a) Croué, V.; Goeb, S.; Szalóki, G.; Allain, M.; Sallé, M. Reversible Guest Uptake/Release by Redox-Controlled Assembly/ Disassembly of a Coordination Cage. Angew. Chem., Int. Ed. 2016, 55, 1746-1750. (b) Szalóki, G.; Croué, V.; Carré, V.; Aubriet, F.; Alévêque, O.; Levillain, E.; Allain, M.; Aragó, J.; Ortí, E.; Goeb, S.; Sallé, M. Controlling the Host-Guest Interaction Mode through a Redox Stimulus. Angew. Chem., Int. Ed. 2017, 56, 16272-16276.

(19) (a) Xu, L.; Zhang, D.; Ronson, T. K.; Nitschke, J. R. Improved Acid Resistance of a Metal-Organic Cage Enables Cargo Release and Exchange between Hosts. Angew. Chem., Int. Ed. 2020, 59, 74357438. (b) Jansze, S. m.; Severin, K. Palladium-Based Metal-Ligand Assemblies: The Contrasting Behavior upon Addition of Pyridine or Acid. J. Am. Chem. Soc. 2019, 141, 815-819.

(20) Jansze, S. M.; Cecot, G.; Severin, K. Reversible Disassembly of Metallasupramolecular Structures Mediated by a Metastable-State Photoacid. Chem. Sci. 2018, 9, 4253-4257.
(21) (a) Kathan, M.; Hecht, S. Photoswitchable molecules as key ingredients to drive systems away from the global thermodynamic minimum. Chem. Soc. Rev. 2017, 46, 5536-5550. (b) Petermayer, C.; Dube, H. Indigoid Photoswitches: Visible Light Responsive Molecular Tools. Acc. Chem. Res. 2018, 51, 1153-1163. (c) Wiedbrauk, S.; Bartelmann, T.; Thumser, S.; Mayer, P.; Dube, H. Simultaneous complementary photoswitching of hemithioindigo tweezers for dynamic guest relocalization. Nat. Commun. 2018, 9, 1456-1465. (d) Siewertsen, R.; Neumann, H.; Buchheim-Stehn, B.; Herges, R.; Nather, C.; Renth, F.; Temps, F. Highly Efficient Reversible Z-E Photoisomerization of a Bridged Azobenzene with Visible Light through Resolved S1(n $\left.\pi^{*}\right)$ Absorption Bands. J. Am. Chem. Soc. 2009, 131, 15594-15595. (e) Hammerich, M.; Schütt, C.; Stähler, C.; Lentes, P.; Röhricht, F.; Höppner, R.; Herges, R. Heterodiazocines: Synthesis and Photochromic Properties, Trans to Cis Switching within the Bio-optical Window. J. Am. Chem. Soc. 2016, 138, 1311113114. (f) Klajn, R.; Stoddart, J. F.; Grzybowski, B. A. Nanoparticles functionalised with reversible molecular and supramolecular switches. Chem. Soc. Rev. 2010, 39, 2203-2237. (g) Mallo, N.; Foley, E. D.; Iranmanesh, H.; Kennedy, A. D. W.; Luis, E. T.; Ho, J.; Harper, J. B.; Beves, J. E. Structure-function relationships of donor-acceptor Stenhouse adduct photochromic switches. Chem. Sci. 2018, 9, 82428252.

(22) (a) Han, M.; Michel, R.; He, B.; Chen, Y.; Stalke, D.; John, M.; Clever, G. H. Light-Triggered Guest Uptake and Release by a Photochromic Coordination Cage. Angew. Chem., Int. Ed. 2013, 52, 1319-1323. (b) Li, R.-J.; Holstein, J. J.; Hiller, W. G.; Andréasson, J.; Clever, G. H. Mechanistic Interplay between Light Switching and Guest Binding in Photochromic [Pd2Dithienylethene4] Coordination Cages. J. Am. Chem. Soc. 2019, 141, 2097-2103. (c) Li, R.; Han, M.; Tessarolo, J.; Holstein, J. J.; Lübben, J.; Dittrich, B.; Volkmann, C.; Finze, M.; Jenne, C.; Clever, G. H. Successive Photoswitching and Derivatization Effects in Photochromic Dithienylethene-Based Coordination Cages. Chemphotochem 2019, 3, 378-383.

(23) (a) Wezenberg, S. J. Light-switchable Metal-Organic Cages. Chem. Lett. 2020, 49, 609-615. (b) Diaz-Moscoso, A.; Arroyave, F. A.; Ballester, P. Moving systems of polar dimeric capsules out of thermal equilibrium by light irradiation. Chem. Commun. 2016, 52, 3046-3049. (c) Diaz-Moscoso, A.; Ballester, P. Light-responsive molecular containers. Chem. Commun. 2017, 53, 4635-4652. (d) Samanta, D.; Gemen, J.; Chu, Z.; Diskin-Posner, Y.; Shimon, L. J. W.; Klajn, R. Reversible photoswitching of encapsulated azobenzenes in water. Proc. Natl. Acad. Sci. U. S. A. 2018, 115, 9379-9384. (e) Canton, M.; Grommet, A. B.; Pesce, L.; Gemen, J.; Li, S.; Diskin-Posner, Y.; Credi, A.; Pavan, G. M.; Andréasson, J.; Klajn, R. Improving Fatigue Resistance of Dihydropyrene by Encapsulation within a Coordination Cage. J. Am. Chem. Soc. 2020, 142, 14557-14565. (f) Wang, W.; Wang, Y. X.; Yang, H. B. Supramolecular transformations within discrete coordination-driven supramolecular architectures. Chem. Soc. Rev. 2016, 45, 2656-2693. (g) Li, M.; Chen, L.-J.; Cai, Y.; Luo, Q.; Li, W.; Yang, H.-B.; Tian, H.; Zhu, W.-H. Light-Driven Chiral Switching of Supramolecular Metallacycles with Photoreversibility. Chem. 2019, 5, 634-648. (h) Zhang, Y.; Zhou, Y.; Gao, T.; Yan, P.; Li, H. Metal-directed synthesis of quadruple-stranded helical $\mathrm{Eu}($ iii) molecular switch: a significant improvement in photocyclization quantum yield. Chem. Commun. 2020, 56, 13213-13216.

(24) Our previous work has demonstrated, however, that the nonconfigurationally stable open-form ligands within the cage architecture can quickly epimerize in solution. See ref 22 . 